\title{
Practical Challenges-Use of Paracetamol in Children and Youth Who are Overweight or Obese: A Narrative Review
}

\author{
William T. Zempsky ${ }^{1} \cdot$ Preeti K. Bhagat $^{2} \cdot$ Kamran Siddiqui $^{2}$
}

Published online: 11 September 2020

(c) The Author(s) 2020

\begin{abstract}
Worldwide, $>380$ million children and adolescents are overweight or obese, including 41 million children aged $<5$ years. Obesity can change the pharmacokinetic properties of drugs by altering their distribution, metabolism, and elimination. Thus, children who are overweight or obese are at increased risk for receiving inappropriate doses of commonly used drugs, which can result in treatment failure, adverse events, and/or drug toxicity. This review analyzes available data on paracetamol dosing for pain and fever in children and adolescents who are overweight or obese to identify gaps and challenges in optimal dosing strategies. Literature searches using Medline, Embase, and ClinicalTrials.gov were conducted to identify English-language articles reporting paracetamol pharmacokinetics, dosing practices, and guidelines in children and adolescents who are overweight or obese. Of 24 relevant studies identified, 20 were specific to overweight/obese individuals and 15 were specific to children and/or adolescents. Data on paracetamol pharmacokinetics in children and adolescents who are overweight or obese are lacking, and there is no high-quality evidence to guide paracetamol prescribing practices in these patients. Adult data have been extrapolated to pediatric populations; however, extrapolation does not address differences in paracetamol metabolism in adults versus children; the efficacy and safety effects of such differences are unknown. Given the growing worldwide prevalence of obesity in children and adolescents and the likelihood that paracetamol use in this population will increase accordingly, obesity-specific pediatric dosing guidelines for paracetamol are urgently needed. High-quality research is necessary to inform such guidelines.
\end{abstract}

\section{Introduction}

The increasing prevalence of overweight and obesity among children and adolescents is a serious global public health problem associated with increased risks of cardiovascular disease, diabetes, and other adverse health outcomes [1-4]. In children, obesity is a predictor of premature death and disability in adulthood and increases the risk for respiratory, musculoskeletal, cardiometabolic, and psychological disorders [3].

Pain has been reported as a common comorbidity in children who are overweight or obese [5-8]. Children with obesity have a greater risk of chronic pain and of any pain,

William T. Zempsky

wzempsk@connecticutchildrens.org

1 Department of Pediatrics, Connecticut Children's Medical Center, University of Connecticut, 282 Washington St, Hartford, CT 06106, USA

2 Consumer Healthcare R \& D, GlaxoSmithKline Consumer Healthcare, Singapore, Singapore

\section{Key Points}

The global population of children and adolescents who are overweight or obese is large and increasing rapidly; because these patients are at increased risk for pain, the use of analgesics, including paracetamol, can be expected to increase correspondingly.

The choice of safe and effective paracetamol doses for pediatric patients who are overweight or obese is challenging because neither age- nor weight-based dosing guidelines properly account for differences in fat versus lean body mass and their possible effects on paracetamol pharmacokinetics and metabolism in this population.

There is an important and growing unmet need for robust data on paracetamol disposition and pharmacokinetics in this population to support the development of evidencebased guidelines from international/national healthcare institutions and/or professional societies that address dosing strategies in children and adolescents who are overweight or obese. 
and report increased pain duration and disability, compared with normal-weight children $[5,6,9]$. Pain was a current comorbidity in $47 \%$ and $58 \%$ of pediatric patients presenting for a weight-management program or for bariatric surgery, respectively [7, 8]. Furthermore, patients reporting pain in the weight-management program had significantly higher body mass index (BMI) than those reporting no pain $(P<0.05)$ [8]. The high prevalence of comorbid pain in overweight and obese pediatric populations suggests that analgesic use can be expected to be more common in this population than in normal-weight children.

Selected criteria for overweight and obesity, including those from the World Health Organization (WHO) and the US Centers for Disease Control and Prevention (CDC), are listed in Table 1 [10-15]. According to WHO estimates for 2016, approximately 381 million children and adolescents may be overweight or obese worldwide, including some 41 million children younger than 5 years of age and 340 million children and adolescents aged 5-19 years [3]. Worldwide, an estimated $5.6 \%$ of girls (50 million) and $7.8 \%$ of boys (74 million) aged 5-19 years are obese (defined as BMI $>2$ standard deviations above the WHO growth standard median); however, prevalence rates of pediatric overweight and obesity vary substantially by geographic region [13]. Notably, rates of pediatric overweight and obesity are rising in low- and middle-income countries; currently nearly half of all children who are overweight or obese aged $<5$ years live in Asia [3]. The highest rates of childhood obesity $(\geq 20 \%$ ) have been reported in Polynesia, Micronesia, the Middle East, North Africa, the Caribbean, and the United States. Obesity prevalence is also notably high in other high-income, English-speaking regions, including Australia, Canada, and the United Kingdom. Conversely, childhood obesity rates are lowest $(<1-2 \%)$ in certain African and Asia-Pacific countries (e.g., Cambodia, Vietnam, Ethiopia, India, and Japan) [13].

For paracetamol (United States Adopted Name [USAN]: acetaminophen), the WHO and some country-specific guidelines recommend dosing based on weight, in the range of $10-15 \mathrm{mg} / \mathrm{kg}$ (up to a maximum daily dose of $60 \mathrm{mg} / \mathrm{kg}$ ) for infants and children (up to ages 12 or 18 years depending on country-specific guidelines and/or product formulation) [16-18]. However, these guidelines do not provide specific recommendations for paracetamol dosing in children and adolescents who are overweight or obese.

Drug dosing may be challenging in overweight and obese populations because obesity causes physiologic changes in tissue composition, circulating blood volume and flow distribution, cardiac output, and liver and kidney function [19-21]. Additionally, children with obesity have been shown to have greater fat mass, hydration of lean mass, and bone mineral content than normal-weight children [22, 23]. These obesity-related changes can affect the pharmacokinetic properties of many drugs. For example, in adults it is known that paracetamol clearance increases and exposure decreases with increasing body weight and that the clearance in patients who are obese is significantly greater than in normal-weight and overweight controls, which can potentially result in therapeutic failure [24-28].

This narrative review explores the available data on paracetamol dosing in children and adolescents who are overweight or obese to identify gaps and challenges in developing safe and effective dosing strategies. A narrative, rather than systematic, review approach was used primarily because of the paucity of well-designed studies and data with respect to paracetamol dosing in the population of interest, which indicates in itself a significant unmet need.

\section{Methods of Literature Review}

Literature searches using Medline, Embase, and ClinicalTrials.gov were conducted to identify English-language articles indexed from database inception through June 11, 2020 with information on paracetamol dosing and pharmacokinetics in individuals with obesity. Initial searches focused only on

Table 1 Global definitions of overweight and obese in children and adolescents [10-15]

\begin{tabular}{ll}
\hline Criteria & Definitions $^{\mathrm{a}}$ \\
\hline WHO, birth to age 5 years & $\begin{array}{l}\text { Overweight: BMI }>2 \text { SD above WHO growth standard median } \\
\text { Obese: BMI }>3 \text { SD above WHO growth standard median }\end{array}$ \\
WHO, age 5-19 years & Overweight: BMI $>1$ SD above WHO growth standard median \\
& Obese: BMI $>2$ SD above WHO growth standard median \\
CDC, age 2-19 years, age- and sex-specific growth charts & Overweight: $\geq 85$ th and $<95$ th percentile \\
& Obese: $\geq 95$ th percentile \\
International Obesity Task Force, age 2-18 years & International BMI cut points by age and sex correspond to adult \\
& BMI $\geq 25 \mathrm{~kg} / \mathrm{m}^{2}$ (overweight) and BMI $\geq 30 \mathrm{~kg} / \mathrm{m}^{2}(\mathrm{obese})$ \\
\hline
\end{tabular}

$B M I$ body mass index, $C D C$ US Centers for Disease Control and Prevention, $k g$ kilogram, $m$ meter, $S D$ standard deviation, WHO World Health Organization

${ }^{\text {a}}$ Percentiles compare an individual's height and weight to others of the same age and sex 
pediatric and adolescent populations; however, very few articles were identified using this strategy. Therefore, searches were broadened to include both adults and children.

A search to identify articles reporting on paracetamol dosing in individuals who are overweight or obese used the following search terms in the title or abstract: [(acetaminophen OR paracetamol OR APAP) AND (overweight OR obese OR obesity OR body mass) AND (dose* OR dosing OR dosage)]. A subsequent search to identify articles focused on paracetamol pharmacokinetics in individuals who are overweight or obese used the following search terms in the title or abstract: [(acetaminophen OR paracetamol OR APAP) AND (pharmacokinetic* OR PK) AND (overweight OR obese OR obesity OR body mass)]. To identify articles providing paracetamol dosing guidelines in individuals who are overweight or obese, the following unrestricted search was performed: [(acetaminophen OR paracetamol OR APAP) AND (guideline*) AND (dose* or dosing) AND (weight OR obese OR obesity OR "body mass")]. Searches of sources that are publicly available through non-indexed sources (e.g., government, academic, business, and industry research that is not formally published) were performed using combinations of the search terms above to identify additional dosing guidelines and to identify ongoing clinical trials of paracetamol in populations of overweight or obese individuals.

The abstracts of all articles identified in these searches were evaluated for relevance. Full-text articles were obtained for all potentially relevant publications. References included in these full-text articles also were evaluated to identify any relevant publications that were not found in literature searches using Medline.

\section{Results of Literature Review}

\subsection{Search Results}

Literature searches using Medline and Embase identified a total of 155 articles; 24 of these publications were relevant. This is a narrative review, and as such, no standard protocol for systematic literature reviews was followed. Twenty articles provided data specific to individuals who were overweight and/or obese. Fifteen articles included data specific to children and/or adolescents. Nine articles focused on adults. The key topics discussed in the articles on children/adolescents who were overweight and/or obese include pharmacokinetics (two articles), dosing (six articles), and guidelines (four articles).

Searches of ClinicalTrials.gov and gray literature searches identified three registered clinical trials relevant to the use of paracetamol in children or adolescents who are overweight or obese (Table 2). Two of these studies have very small sample sizes and recent (within the past year) updates; the third, while larger, has not been updated since 2011 and may have been abandoned. Searches did not find any publications associated with these trials. This suggests that their findings, if any, are unlikely to provide much useful information to help guide paracetamol dosing in children and adolescents who are overweight or obese.

\subsection{Pharmacokinetic Data to Guide Paracetamol Dosing in Overweight/Obese Children and Adolescents}

Data on the pharmacokinetics of paracetamol in children and adolescents who are overweight or obese are extremely limited. Two small pediatric studies in children/adolescents who were overweight or obese were identified, and these studies were limited to specific subgroups of patients who are overweight or obese that may not be generalizable to broader populations. One study enrolled male children and adolescents aged 10-17 years with nonalcoholic fatty liver disease (NAFLD) [29]. The other (single-arm) study enrolled female adolescents aged 14-20 years with morbid obesity [26]. Therefore, meaningful comparisons could not be made between the pharmacokinetic properties of paracetamol in general populations of overweight/obese versus normal-weight children and adolescents. Results of these two studies are summarized below, together with results of a single study that assessed the effect of body weight on paracetamol pharmacokinetics in pediatric patients with BMI in the normal range [30].

Barshop and colleagues performed a matched case-control study evaluating the pharmacokinetics of paracetamol in 12 boys aged $10-17$ years with NAFLD who were generally obese (mean BMI $=34.0 \mathrm{~kg} / \mathrm{m}^{2}$ ). The control group comprised 12 boys without NAFLD (mean BMI $=26.2 \mathrm{~kg} / \mathrm{m}^{2}$ ). The mean dose of paracetamol administered was $3.6 \mathrm{mg} /$ $\mathrm{kg}$ (standard deviation \pm 0.8 ) for children with NAFLD and $3.8 \mathrm{mg} / \mathrm{kg}( \pm 0.9)$ for controls. Children with NAFLD, compared with controls, demonstrated elevated concentrations of glucuronide metabolite in plasma (35\% higher at $4 \mathrm{~h}, P$ $=0.0071$ ) and urine (twofold higher at $4 \mathrm{~h}, P=0.0151$ ) of children with NAFLD compared with controls. In contrast, children with NAFLD, compared with controls, demonstrated similar median values for paracetamol peak serum concentration $\left(C_{\max } ; 10.0\right.$ vs $10.1 \mathrm{mg} / \mathrm{L}$, respectively), area under the plasma concentration-time curve (AUC; 12.6 vs $10.2 \mathrm{mg} \mathrm{h}^{-1} \mathrm{~L}^{-1}$ ), elimination half-life ( 2.94 vs $3.52 \mathrm{~h}$ ), and clearance $\left(0.31 \mathrm{~L} \mathrm{~kg}^{-1} \mathrm{~h}^{-1}\right.$, both) [29]. These results should be interpreted with caution because overweight/obesity was not a criterion for inclusion in the study [29], and the presence of nonalcoholic steatohepatitis (a histopathological feature of NAFLD) may have confounded results such that they are not generalizable to broad populations of children 
with obesity [31, 32]. Furthermore, the control group was overweight (mean BMI $>25 \mathrm{~kg} / \mathrm{m}^{2}$ ) and BMI was variable (standard deviation $\pm 10.95 \mathrm{~kg} / \mathrm{m}^{2}$ ), providing little differentiation from the NAFLD group. These results differ from those reported in adults in which paracetamol $C_{\max }$ and AUC were significantly reduced in adults who were overweight versus normal-weight adults [24, 25].

In a single-arm clinical trial, Hakim and colleagues [26] evaluated the pharmacokinetics of a single dose of paracetamol $1000 \mathrm{mg}$ in 11 female adolescents with morbid obesity (mean BMI $=46 \mathrm{~kg} / \mathrm{m}^{2}$, standard deviation $5 \mathrm{~kg} / \mathrm{m}^{2}$ ) aged 14-20 years. Observed data and simulated pharmacokinetic modeling demonstrated that a two-compartment model using allometric scaling provided the best fit to the observed data. Applying allometric scaling to the observed pharmacokinetic data for a $70-\mathrm{kg}$ patient produced an estimated paracetamol clearance value of $0.15 \mathrm{~L} \mathrm{~kg}^{-1} \mathrm{~h}^{-1}$, about half the value observed $\left(0.31 \mathrm{~L} \mathrm{~kg}^{-1} \mathrm{~h}^{-1}\right)$ in the study of boys with NAFLD [29]; however, there was substantial intersubject variability in the small sample (coefficient of variation $=72.1 \%$ ). This is consistent with studies showing increased clearance in adults with obesity $[27,28]$. Simulations based on various paracetamol doses administered to a non-obese $(50-\mathrm{kg})$ adolescent and one with morbid obesity $(125 \mathrm{~kg})$ showed that a paracetamol dose of $2250 \mathrm{mg}$ would be required for an obese adolescent to achieve serum and effect site paracetamol concentrations comparable to those achieved by a non-obese adolescent receiving a 1000-mg dose. The dose that achieved a target concentration of $10 \mathrm{mg} / \mathrm{L}$ in the effect compartment at $2 \mathrm{~h}$ after administration was better predicted based on total body weight using allometric scaling than using linear models [26]. These results are consistent with the nonlinear relationship between total body weight and clearance, and the effects of fat mass on volume of distribution. Although these data suggest that dosing based on allometric scaling may improve therapeutic benefit in adolescents with morbid obesity, the increased dosage required for such individuals may increase the risk of overdose and hepatotoxicity [26].

Studies of drugs other than paracetamol suggest that biotransformation and clearance changes similar to those observed in adults with obesity may also occur in pediatric populations, and that these changes may affect drug exposure in children with obesity $[19,33]$. No studies were identified that specifically evaluated the effect of overweight or obesity on pharmacokinetic properties of paracetamol in children. However, a single study assessed the effect of body weight over a normal range on paracetamol pharmacokinetics; in 33 normal-weight children between 1.8 and 15 years of age with weight ranging from 13.7 to $56 \mathrm{~kg}$ and BMI ranging from 14.1 to $25.4 \mathrm{~kg} / \mathrm{m}^{2}$, total body weight affected the clearance and volume of distribution of intravenously administered paracetamol, as both increased significantly 
with increasing total body weight [30]. It is unclear whether these results can be applied to oral formulations.

\subsection{Paracetamol Dosing Practices in Children Who are Overweight or Obese}

Six studies were identified that provide data on paracetamol dosing patterns in pediatric patients who are overweight or obese. These studies included four retrospective studies conducted in Danish [34], Middle Eastern [35], Italian [36], and American populations [37], an audit of pain management prescriptions in the United Kingdom [38], and a survey and observational study of Australian caregivers and pharmacists [39]. Overall, the studies reported that dosing practices in children who were overweight or obese were variable and findings of incorrect dosing were mixed.

Three studies reported more frequent overdosing in children who were overweight or obese [34, 38, 39]. The retrospective cohort study conducted at the Danish Children's Obesity clinic evaluated dosing strategies in 200 overweight or obese children aged 3-18 years from 2007 to 2015. Of 34 paracetamol prescriptions identified, paracetamol was dosed in 15 cases based on total body weight according to the local pediatric treatment facility standard dosing regimen (not otherwise specified) for normal-weight children [34]. (For reference, the WHO recommends paracetamol dosing of 10-15 $\mathrm{mg} / \mathrm{kg}$ up to a maximum daily dose of $60 \mathrm{mg} / \mathrm{kg}$ for infants and children aged 2 months and older [16]). In nine cases, the calculated dose exceeded the maximum recommended $\mathrm{mg} / \mathrm{kg}$ adult dose and the prescribed dose was capped at the maximum recommended adult dose (not otherwise specified). In three cases, children who were overweight or obese were prescribed paracetamol doses exceeding the calculated dose, and in one case, a child was prescribed a dose exceeding the recommended maximum adult dose. Overall, large individual variations were observed in dosing regimens for drugs with a narrow therapeutic window, including paracetamol [34].

An audit of pain-management paracetamol prescriptions in pediatric surgical patients $(n=100)$ in the United Kingdom showed that dosing according to local prescribing guidelines (using ideal body weight) was frequently exceeded, putting patients at risk for adverse effects. Recommended oral dosing of paracetamol was $20-30 \mathrm{mg} / \mathrm{kg}$ as an initial single dose for perioperative pain management, followed by $15-20 \mathrm{mg} / \mathrm{kg}$ every $4-6 \mathrm{~h}$ (up to $90 \mathrm{mg} / \mathrm{kg} /$ day). Among pediatric patients who were overweight or obese, six received oral paracetamol doses ranging from 17.4 to $30 \mathrm{mg} / \mathrm{kg} /$ dose; four received intravenous (IV) paracetamol doses ranging from 20 to $23 \mathrm{mg} / \mathrm{kg} / \mathrm{dose}$; and four received a combination of oral and IV paracetamol doses ranging from 18 to $24 \mathrm{mg} / \mathrm{kg} / \mathrm{dose}$. A total of six patients who were overweight or obese received oral paracetamol at discharge at doses of 13-33 mg/kg/dose [38].

The survey and observational study in Australia also reported more frequent overdosing in children who were overweight or obese. After an initial survey, Australian caregivers $(n=45)$ and community pharmacists $(n=28)$ were followed to determine paracetamol dosing practices in children who were overweight or obese. Results showed that variability in administered doses by caregivers and pharmacists increased with increasing body weight, reflecting uncertainty about recommended doses in this population. When paracetamol doses were normalized to ideal body weight, children who were overweight or obese were more likely to receive higher doses, increasing risk for toxicity [39].

Two of the remaining three studies reviewed here reported more frequent dosing errors in children who were overweight or obese $[35,36]$. The study conducted in Saudi Arabia reported both under- and overdosing errors in this population. This retrospective analysis evaluated the prevalence of inappropriate medication dosing in overweight and obese children at pediatric ambulatory care clinics from June to December 2013. Of the 2460 children screened, 96 were overweight or obese and received approximately 345 medications during the study period. Across all drugs, inappropriate doses (defined as $>10 \%$ deviation from doses calculated based on Lexicomp and Harriet Lane pediatric reference standards) were prescribed to 66\% (63/96) of overweight or obese children; in these patients, rates of overdosing (51\%) and underdosing (49\%) were similar. Paracetamol was identified as one of the most likely drugs to be prescribed inappropriately, increasing risks for hepatotoxicity or inadequate pain or fever control [35].

Underdosing of paracetamol and ibuprofen was identified as the primary concern in a retrospective study conducted at 17 clinics in Italy ( $n=1471$, not confined to children who were overweight or obese). Paracetamol and ibuprofen were dosed inadequately in 61\% (893/1471) of children based on an appropriate paracetamol dose defined as 15-20 $\mathrm{mg} / \mathrm{kg}$ (1000 mg for children weighing $\geq 50 \mathrm{~kg}$ ). Most of these children (577/893) were prescribed paracetamol. Body weight $>40 \mathrm{~kg}$ was associated with an increased likelihood of underdosing [36].

The sixth study reviewed here reported less frequent dosing errors in children who were overweight or obese than in normal-weight children. In this retrospective study conducted at a single US academic hospital, the potential for analgesic or antimicrobial drug dosing errors was evaluated in 278 overweight or obese (BMI $\geq 85$ th percentile) children aged 5-12 years compared with controls. The most commonly observed overdosing errors were for combination paracetamol/hydrocodone; overdosing of paracetamol alone and combination paracetamol/codeine was rare in children 
who were overweight or obese. Overdosing of paracetamol/ hydrocodone, in which patients received paracetamol doses greater than the recommended $15 \mathrm{mg} / \mathrm{kg} / \mathrm{dose}$, was more common in the control group than in the overweight/obese group (26.4\% vs $14.7 \%$, respectively) [37].

In the studies reviewed, dosing regimens were variable and inappropriate dosing was common in children who were overweight or obese. It is generally accepted that underdosing could lead to suboptimal therapeutic effect and overdosing has the potential to cause toxicities; however, there is an absence of clinical data on this topic. Indeed, none of the studies reviewed here reported adverse events, toxicities, or other sequelae associated with over/underdosing in children who were overweight or obese.

\subsection{Paracetamol Dosing Guidelines that Include Recommendations for Children Who are Overweight or Obese}

Results of our searches indicate that paracetamol dosing guidelines that include specific recommendations for use in children and adolescents who are overweight or obese are extremely limited. In our searches for international, national, professional society, or institutional guidelines/ recommendations on paracetamol dosing in this population, we were able to identify only four children's hospitals (St. Louis Children's Hospital, Royal Children's Hospital Melbourne, Rocky Mountain Hospital for Children, and Sydney Children's Hospital) that provide weight-based, rather than age-based, paracetamol dosing guidelines on their external, publicly accessible websites [40-43]. While weight-based dosing is generally recognized as more accurate than agebased dosing for children whose weight is not within the average range [44, 45], these website guidelines [40-42] and most national, international, and society guidelines for pediatric oral paracetamol dosing [16-18, 45-48] do not include any specific recommendations for patients who are overweight or obese. For example, WHO recommendations specify a maximum daily dosage of $60 \mathrm{mg} / \mathrm{kg} / \mathrm{day}$, but do not address the overweight or obese pediatric population [16]. In the absence of efficacy and safety data resulting from use of the three children's hospital website guidelines, it is not possible to evaluate their relative merits and shortcomings with respect to treatment of pediatric patients who are overweight or obese.

The only sources we identified that provide any guidance for paracetamol dosing in children with obesity are from the Sydney Children's Hospital and the Best Practice Advocacy Centre New Zealand (bpac ${ }^{\mathrm{NZ}}$ ). The Sydney Children's Hospital states that for patients with obesity, paracetamol dose should be calculated based on ideal body weight for age and height; however, formulas or sample calculations are not provided [43]. The bpac ${ }^{\mathrm{NZ}}$ guidelines for paracetamol state that the same $\mathrm{mg} / \mathrm{kg}$ dose calculation should be used for obese and normal-weight children, but that the adult dose should never be exceeded [17].

The British National Formulary for Children (BNFC) and the UK National Health Service recommend age-based dosing for the management of pain or fever with discomfort in children aged 3 months to 12 years [47]. Although the BNFC guidelines were updated in 2011 to include narrower age bands than those listed on the labels of many commonly used over-the-counter products, calculations based on UKWHO growth charts using these guidelines yielded inappropriate calculated doses for both overweight and underweight children [49]. One rationale for age- instead of weight-based dosing is that weight-based calculations can be difficult for caregivers [50], highlighting a significant unmet need for clearer package insert guidelines.

The absence of evidence-based guidelines from international or national health institutions or professional specialty-based societies with respect to paracetamol dosing in children/adolescents who are overweight or obese constitutes an important unmet need.

\section{Discussion}

In general, optimization of drug dosing in children who are overweight or obese is particularly difficult because very few studies have evaluated obesity-related pharmacokinetic changes of commonly prescribed medications in pediatric or adolescent populations [51]. Attempts have been made to develop methods to calculate medication doses in children who are overweight or obese, based on standardized measures of body weight/size (Table 3 [34, 52]). Although dosing aids and decision-support tools have been developed to help parents and practitioners determine and administer appropriate paracetamol doses in these patients [53, 54], these calculation methods and tools are not supported by robust clinical data. The body size metrics of ideal or adjusted body weight can be used, but these methods often result in underdosing [35]. Dosing based on BMI or body surface area can result in overdosing, with calculated doses exceeding the maximum recommended total dose [35]. Additionally, data have shown ideal body weight calculation methods are not standardized, and the concept of ideal body weight is poorly understood among pediatricians $[51,55]$.

Body weight affects drug disposition characteristics, and this effect will be compounded by other physiologic changes associated with obesity. Drug disposition in patients with obesity can be altered because of, for example, changes in lipid parameters and the proportion of adipose tissue versus lean muscle mass, neither of which are accounted for in BMI calculations [19-21]. The degree and direction of changes in specific pharmacokinetic parameters are dependent on the 
drug; for example, acetaminophen clearance increases with increased weight, but the reverse is true for antipyrine [19, $27,56]$. As a result, patients who are overweight or obese are at increased risk for receiving inappropriate doses of medication [19, 33-35, 57].

Clearly, the most critical pharmacokinetic consideration in paracetamol dosing for obese patients is clearance, which has been shown to be increased in adults with obesity $[27,28]$. This would suggest that patients with obesity may require higher doses than currently recommended by guidelines/formularies to achieve paracetamol levels that are associated with therapeutic benefit [27, 28]. However, the ability to increase paracetamol dosing to achieve therapeutic efficacy in response to increased clearance is limited by the absolute maximum allowed dose of $4000 \mathrm{mg}$ /day in children/adolescents [58].

The prescribing information and package inserts for paracetamol provide a recommended dosing chart based on both age and corresponding body weight. This may introduce uncertainty for children who are overweight or obese, since their weight is outside normal age-based weight ranges [39]. Because of such complexities in determining the most appropriate metric to use in dose calculation for pediatric patients who are overweight or obese, optimal dosing of paracetamol in this population remains uncertain [26,33].

Results of our narrative literature review confirm that specific dosing guidance for paracetamol in children and adolescents who are overweight or obese is extremely limited or absent [33, 59]. Incorrect paracetamol dosing in such patients is a recognized risk factor for treatment failure [60].

Current weight-based dosing guidelines for paracetamol $(10-15 \mathrm{mg} / \mathrm{kg}$, up to a maximum daily dose of $60 \mathrm{mg} / \mathrm{kg}$ [16-18]) have been developed based on concerns about reduced efficacy, and are not based on robust pharmacokinetic or pharmacodynamic data. For example, although one study suggested similar paracetamol pharmacokinetic behavior between NAFLD patients and normal-weight

Table 3 Measures used to calculate medication doses in overweight/ obese children [34, 52]

\begin{tabular}{ll}
\hline Dosing criteria & Measurement \\
\hline Age & Age in years \\
Total body weight (TBW) & Weight in $\mathrm{kg}$ \\
Body mass index (BMI) & TBW/height ${ }^{2}\left(\mathrm{~kg} / \mathrm{m}^{2}\right)$ \\
Ideal body weight (IBW) & BMI at the 50 th percentile \\
& for age and sex $\times$ height \\
Lean body weight $(\mathrm{LBW})$ & IBW $+0.29 \times(\mathrm{TBW}-\mathrm{IBW})$ \\
Adjusted body weight $(\mathrm{ABW})$ & $\mathrm{IBW}+(0.4 \times[\mathrm{TBW}-\mathrm{IBW}])$ \\
\hline
\end{tabular}

$A B W$ actual body weight, $B M I$ body mass index, $I B W$ ideal body weight, $\mathrm{kg}$ kilogram, $m$ meter, $T B W$ total body weight

${ }^{\text {a}}$ Percentiles compare an individual's height and weight to others of the same age and sex counterparts [26], the study was so small (and not specific to obesity) that it remains unknown whether the increased paracetamol clearance observed in adults also affects children/adolescents who are overweight or obese. The lack of pharmacokinetic and pharmacodynamic data for paracetamol in children and adolescents who are overweight or obese is a significant data gap [61].

Modeling and simulation can be used as research tools to help bridge this data gap, but wide implementation in pediatric drug development has not occurred [62]. However, one group modified a physiologically based pharmacokinetic model for adults to account for the physiologic changes that occur in children/adolescents from birth to 18 years of age. Using paracetamol as a model compound, simulated plasma concentration-time profiles in children/adolescents closely matched experimentally observed data in adults [63]. This model considers body weight, tissue composition, organ weights, and other variables known to differ significantly in obese versus non-obese children [63]. However, the model is not specific to children and adolescents with obesity. Further research may elucidate whether data from adult studies of paracetamol pharmacokinetics can be used to inform dosing guidance in children who are overweight or obese.

Despite potentially promising modeling results from Edginton and colleagues [63], extrapolation of paracetamol pharmacokinetic and dosing data from adult studies to pediatric populations should be done with extreme caution [64]. Paracetamol clearance mechanisms and half-life have been shown to differ in children (sulfation) compared with adults (glucuronidation), gradually changing as children age. Furthermore, the elimination half-life for paracetamol varies with age between neonates, infants, children, and adolescents [65].

\section{Conclusion}

Literature searches have identified significant gaps in our understanding of the pharmacokinetic behavior of paracetamol, and in clinical data assessing various dosing strategies in children and adolescents who are overweight or obese. As a result, there are limited data on which to base the development of evidence-based guidelines, which explains the lack of currently available paracetamol dosing recommendations in overweight and obese pediatric and adolescent populations. Incorrect dosing can result in suboptimal efficacy and/ or increased risk for adverse outcomes, most notably hepatotoxicity. There is a strong need for well-designed studies in conjunction with pharmacokinetic and pharmacodynamic modeling to confirm the magnitude of changes and characterize metabolite formation (e.g., sulfation and glucuronidation) to provide needed data for evidence-based dosing guidance. Pending the availability of reliable, consensus-based 
guidelines, practitioners should employ dosing strategies with which they are most comfortable (for many, this will represent modification of weight-based dosing), with the minimization of hepatotoxicity risk the paramount concern. Furthermore, practitioners should caution caregivers of children who are overweight or obese to seek medical advice before applying weight-based dosing to minimize the risk of accidental paracetamol overdose.

Acknowledgements Medical writing assistance was provided to the authors by Peloton Advantage, an OPEN Health company, Parsippany, $\mathrm{NJ}$, and funded by GSK Consumer Healthcare.

\section{Declarations}

Funding This article was funded by GSK Consumer Healthcare.

Conflict of interest Kamran Siddiqui and Preeti K. Bhagat are employees of GlaxoSmithKline Consumer Healthcare, Singapore. William Zempsky is a consultant for Pfizer, Endo Pharmaceuticals, GlaxoSmithKline, and Vapogenix; he has received funding from the National Institutes of Health, the US Department of Defense, and the Mayday Fund.

Ethics approval Not applicable (review article).

Consent to participate Not applicable (review article).

Consent for publication Not applicable (review article).

Availability of data and material Not applicable (review article).

Code availability Not applicable (review article).

Author contributions All authors contributed to the conception of this narrative review. All authors substantially reviewed and revised the manuscript for important intellectual content and approved the final manuscript for submission

Open Access This article is licensed under a Creative Commons Attribution-NonCommercial 4.0 International License, which permits any non-commercial use, sharing, adaptation, distribution and reproduction in any medium or format, as long as you give appropriate credit to the original author(s) and the source, provide a link to the Creative Commons licence, and indicate if changes were made. The images or other third party material in this article are included in the article's Creative Commons licence, unless indicated otherwise in a credit line to the material. If material is not included in the article's Creative Commons licence and your intended use is not permitted by statutory regulation or exceeds the permitted use, you will need to obtain permission directly from the copyright holder. To view a copy of this licence, visit http://creativecommons.org/licenses/by-nc/4.0/.

\section{References}

1. Lobstein T, Baur L, Uauy R. Obesity in children and young people: a crisis in public health. Obes Rev. 2004;5(suppl 1):4-104.

2. Gungor NK. Overweight and obesity in children and adolescents. J Clin Res Pediatr Endocrinol. 2014;6(3):129-43.
3. World Health Organization. Obesity and overweight fact sheet. Geneva, Switzerland: World Health Organization. 2018. https:// www.who.int/news-room/fact-sheets/detail/obesity-and-overw eight. Accessed 23 June 2020.

4. Skinner AC, Ravanbakht SN, Skelton JA, Perrin EM, Armstrong SC. Prevalence of obesity and severe obesity in US children, 1999-2016. Pediatrics. 2018;141(3):e20173459.

5. Santos M, Murtaugh T, Pantaleao A, Zempsky WT, Guite JW. Chronic pain and obesity within a pediatric interdisciplinary pain clinic setting: a preliminary examination of current relationships and future directions. Clin J Pain. 2017;33(8):738-45.

6. Grout RW, Thompson-Fleming R, Carroll AE, Downs SM. Prevalence of pain reports in pediatric primary care and association with demographics, body mass index, and exam findings: a crosssectional study. BMC Pediatr. 2018;18(1):363.

7. Zeller MH, Inge TH, Modi AC, Jenkins TM, Michalsky MP, Helmrath M, et al. Severe obesity and comorbid condition impact on the weight-related quality of life of the adolescent patient. J Pediatr. 2015;166(3):651.e4-659.e4.

8. Hainsworth KR, Miller LA, Stolzman SC, Fidlin BM, Davies WH, Weisman SJ, et al. Pain as a comorbidity of pediatric obesity. Infant Child Adolesc Nutr. 2012;4(5):315-20.

9. Deere KC, Clinch J, Holliday K, McBeth J, Crawley EM, Sayers A, et al. Obesity is a risk factor for musculoskeletal pain in adolescents: findings from a population-based cohort. Pain. 2012;153(9):1932-8

10. de Onis M, Onyango AW, Borghi E, Siyam A, Nishida C, Siekmann J. Development of a WHO growth reference for schoolaged children and adolescents. Bull World Health Organ. 2007;85(9):660-7.

11. Cole TJ, Bellizzi MC, Flegal KM, Dietz WH. Establishing a standard definition for child overweight and obesity worldwide: international survey. BMJ. 2000;320(7244):1240-3.

12. Kumar S, Kelly AS. Review of childhood obesity: from epidemiology, etiology, and comorbidities to clinical assessment and treatment. Mayo Clin Proc. 2017;92(2):251-65.

13. NCD Risk Factor Collaboration (NCD-RisC). Worldwide trends in body-mass index, underweight, overweight, and obesity from 1975 to 2016: a pooled analysis of 2416 population-based measurement studies in 128.9 million children, adolescents, and adults. Lancet. 2017;390(10113):2627-42.

14. Monasta L, Lobstein T, Cole TJ, Vignerova J, Cattaneo A. Defining overweight and obesity in pre-school children: IOTF reference or WHO standard? Obes Rev. 2011;12(4):295-300.

15. Defining childhood obesity. Atlanta, GA: Centers for Disease Control and Prevention. 2018. https://www.cdc.gov/obesity/childhood/ defining.html. Accessed 23 June 2020.

16. World Health Organization. Pocket book of hospital care for children. Guidelines for the management of common childhood illnesses. 2nd ed. Geneva: World Health Organization; 2013.

17. Paracetamol dosing for children in primary care. Dunedin, New Zealand: Best Practice Advocacy Centre New Zealand. 2018. https://bpac.org.nz/2018/docs/paracetamol.pdf. Accessed 23 June 2020.

18. Recommended paracetamol doses. Therapeutic Goods Administration, Australian Government Department of Health. 2019. https://www.tga.gov.au/community-qa/recommended-paracetamo 1-doses. Accessed 23 June 2020

19. van Ginkel MWH, Hill KD, Becker KC, Testoni D, CohenWolkowiez M, Gonzalez D, et al. Drug dosing and pharmacokinetics in children with obesity: a systematic review. JAMA Pediatr. 2015;169(7):678-85.

20. Anderson BJ, Holford NH. Getting the dose right for obese children. Arch Dis Child. 2017;102(1):54-5.

21. Cheymol G. Effects of obesity on pharmacokinetics implications for drug therapy. Clin Pharmacokinet. 2000;39(3):215-31. 
22. Wells JC, Fewtrell MS, Williams JE, Haroun D, Lawson MS, Cole TJ. Body composition in normal weight, overweight and obese children: matched case-control analyses of total and regional tissue masses, and body composition trends in relation to relative weight. Int J Obes (Lond). 2006;30(10):1506-13.

23. Mulla H, Johnson TN. Dosing dilemmas in obese children. Arch Dis Child Educ Pract Ed. 2010;95(4):112-7.

24. Goday Arno A, Farre M, Rodriguez-Morato J, Ramon JM, PerezMana C, Papaseit E, et al. Pharmacokinetics in morbid obesity: influence of two bariatric surgery techniques on paracetamol and caffeine metabolism. Obes Surg. 2017;27(12):3194-201.

25. Lee WH, Kramer WG, Granville GE. The effect of obesity on acetaminophen pharmacokinetics in man. J Clin Pharmacol. 1981;21(7):284-7.

26. Hakim M, Anderson BJ, Walia H, Tumin D, Michalsky MP, Syed A, et al. Acetaminophen pharmacokinetics in severely obese adolescents and young adults. Paediatr Anaesth. 2019;29(1):20-6.

27. Abernethy DR, Divoll M, Greenblatt DJ, Ameer B. Obesity, sex, and acetaminophen disposition. Clin Pharmacol Ther. 1982;31(6):783-90.

28. van Rongen A, Valitalo PAJ, Peeters MYM, Boerma D, Huisman FW, van Ramshorst B, et al. Morbidly obese patients exhibit increased CYP2E1-mediated oxidation of acetaminophen. Clin Pharmacokinet. 2016;55(7):833-47.

29. Barshop NJ, Capparelli EV, Sirlin CB, Schwimmer JB, Lavine JE. Acetaminophen pharmacokinetics in children with nonalcoholic fatty liver disease. J Pediatr Gastroenterol Nutr. 2011;52(2):198-202.

30. Mohammed BS, Engelhardt T, Cameron GA, Cameron L, Hawksworth GM, Hawwa AF, et al. Population pharmacokinetics of single-dose intravenous paracetamol in children. $\mathrm{Br} \mathrm{J}$ Anaesth. 2012;108(5):823-9.

31. Vaughns JD, Ziesenitz VC, van den Anker JN. Clinical pharmacology of frequently used intravenous drugs during bariatric surgery in adolescents. Curr Pharm Des. 2015;21(39):5650-9.

32. Michaut A, Moreau C, Robin MA, Fromenty B. Acetaminopheninduced liver injury in obesity and nonalcoholic fatty liver disease. Liver Int. 2014;34(7):e171-9.

33. Kyler KE, Wagner J, Hosey-Cojocari C, Watt K, Shakhnovich V. Drug dose selection in pediatric obesity: available information for the most commonly prescribed drugs to children. Paediatr Drugs. 2019;21(5):357-69.

34. Gade C, Christensen HR, Dalhoff KP, Holm JC, Holst H. Inconsistencies in dosage practice in children with overweight or obesity: a retrospective cohort study. Pharmacol Res Perspect. 2018;6(3):e00398.

35. Alazmi A, Khan M, Goronfolah L, Abulezz R. The prevalence of inappropriate medication dose in overweight and obese children in KAMC, Jeddah. Pediatr Ther. 2016;6(1):1000271.

36. Milani GP, Benini F, Dell'Era L, Silvagni D, Podesta AF, Mancusi RL, et al. Acute pain management: acetaminophen and ibuprofen are often under-dosed. Eur J Pediatr. 2017;176(7):979-82.

37. Miller JL, Johnson PN, Harrison DL, Hagemann TM. Evaluation of inpatient admissions and potential antimicrobial and analgesic dosing errors in overweight children. Ann Pharmacother. 2010;44(1):35-42.

38. McArtney R, Atkinson A. Audit of paracetamol prescriptions in paediatric surgical patients. Arch Dis Child. 2016;101(9):A19.

39. Wiese MD, Sluggett JK, Wilson CJ, Reuter SE, Turner SC, Evans AM. Perceived and actual paracetamol dosing in overweight and obese children. Eur J Hosp Pharm. 2012;19(5):438-42.

40. Acetaminophen dosage chart for children and infants. St. Louis Childrens Hospital. 2019. https://www.stlouischildrens.org/healt h-resources/dosage-tables/acetaminophen-tylenol-dosage-table. Accessed 23 June 2020.
41. Clinical practice guidelines: analgesia and sedation. Melbourne, Australia: The Royal Children's Hospital. 2016. https://www.rch. org.au/clinicalguide/guideline_index/Analgesia_and_sedation/. Accessed 23 June 2020.

42. Acetaminophen and ibuprofen dosing charts. Denver, CO: Rocky Mountain Hospital for Children. 2019. https://rockymountainho spitalforchildren.com/parent-resources/medication-dosing-chart s/. Accessed 23 June 2020.

43. Sydney Children's Hospital. Drug dosing for overweight and obese patients: practice guidelines. Sydney, Australia: Sydney Children's Hospital. 2013. http://www.schn.health.nsw.gov.au/_ policies/pdf/2013-7034.pdf. Accessed 23 June 2020.

44. Temple AR. Pediatric dosing of acetaminophen. Pediatr Pharmacol (New York). 1983;3(3-4):321-7.

45. Chiappini E, Principi N, Longhi R, Tovo PA, Becherucci P, Bonsignori $\mathrm{F}$, et al. Management of fever in children: summary of the Italian Pediatric Society guidelines. Clin Ther. 2009;31(8):1826-43.

46. Safe and appropriate use of paracetamol: closing the consumer knowledge gap. Surry Hills, NSW, Australia: NPS MedicineWise. 2015. https://www.nps.org.au/news/safe-and-appropriate-use-ofparacetamol-closing-the-consumer-knowledge-gap. Accessed 23 June 2020

47. Paracetamol for children (including Calpol). National Health Services United Kingdom. 2019. https://www.nhs.uk/medicines/parac etamol-for-children/. Accessed 23 June 2020.

48. Fever in under $5 \mathrm{~s}$ : assessment and initial management draft for consultation: National Institute for Health and Care Excellence. 2019. https://www.nice.org.uk/guidance/GID-NG10138/docum ents/draft-guideline. Accessed 23 June 2020.

49. Eyers S, Fingleton J, Eastwood A, Perrin K, Beasley R. British National Formulary for Children: the risk of inappropriate paracetamol prescribing. Arch Dis Child. 2012;97(3):279-82.

50. Brass EP, Reynolds KM, Burnham RI, Green JL. Medication errors with pediatric liquid acetaminophen after standardization of concentration and packaging improvements. Acad Pediatr. 2018;18(5):563-8.

51. Russell H, Bourne K. Drug dose adjustments in obese paediatric patients [abstract]. Arch Dis Child. 2015;100(6):P31.

52. Callaghan LC. Prescribing in paediatric obesity: methods to improve dosing safety in weight-based dose calculations. Arch Dis Child Educ Pract Ed. 2018;103(5):274-7.

53. Ross EL, Heizer J, Mixon MA, Jorgensen J, Valdez CA, Czaja AS, et al. Development of recommendations for dosing of commonly prescribed medications in critically ill obese children. Am J Health Syst Pharm. 2015;72(7):542-56.

54. Hixson R, Franke U, Mittal R, Hamilton M. Parental calculation of pediatric paracetamol dose: a randomized trial comparing the parental analgesia slide with product information leaflets. Paediatr Anaesth. 2010;20(7):612-9.

55. Collier H, Nasim M, Gandhi A. Prescribing in obese children: how good are paediatricians? Arch Dis Child. 2017;102(1):61-2.

56. Abernethy DR, Greenblatt DJ. Pharmacokinetics of drugs in obesity. Clin Pharmacokinet. 1982;7(2):108-24.

57. Burke CN, Voepel-Lewis T, Wagner D, Lau I, Baldock A, Malviya $S$, et al. A retrospective description of anesthetic medication dosing in overweight and obese children. Paediatr Anaesth. 2014;24(8):857-62.

58. Squires RH Jr, Shneider BL, Bucuvalas J, Alonso E, Sokol RJ, Narkewicz MR, et al. Acute liver failure in children: the first 348 patients in the pediatric acute liver failure study group. J Pediatr. 2006;148(5):652-8.

59. Kendrick JG, Carr RR, Ensom MH. Pediatric obesity: pharmacokinetics and implications for drug dosing. Clin Ther. 2015;37(9):1897-923.

60. Beggs S. Paediatric analgesia. Aust Prescr. 2008;31(3):63-5. 
61. Kaul A, Adil MS. Drug dosing in obese patients: a dilemma. Int J Adv Pharm. 2014;3(6):59-65.

62. Bellanti F, Della Pasqua O. Modelling and simulation as research tools in paediatric drug development. Eur J Clin Pharmacol. 2011;67(suppl 1):75-86.

63. Edginton AN, Schmitt W, Willmann S. Development and evaluation of a generic physiologically based pharmacokinetic model for children. Clin Pharmacokinet. 2006;45(10):1013-34.
64. Cella M, Knibbe C, Danhof M, Della Pasqua O. What is the right dose for children? Br J Clin Pharmacol. 2010;70(4):597-603.

65. Moriarty C, Carroll W. Paracetamol: pharmacology, prescribing and controversies. Arch Dis Child Educ Pract Ed. 2016;101(6):331-4. 